\title{
New vaccines are aimed at the rich says UNICEF
}

Speaking at the World Bank meeting on vaccine development and delivery this March in Washington D.C., the Executive Director of United Nations Children's Fund (UNICEF) Carol Bellamy, criticized current vaccine $R \& D$ programs for targeting diseases that occur in rich countries.

Bellamy complained that even efforts to develop an HIV vaccine are focusing on variants of the virus that affect people in Europe and North America rather than Africa and Asia. Although she recognized that significant advances have been made in the



Carol Bellamy million infant deaths per year. "But before they can be used on a wide scale, their effectiveness must be carefully assessed in clinical trials in developing countries," Bellamy continued, "WHO is prepared to conduct these assessments within the next three years-a job that will require about $\$ 20$ million." Development of vaccines against diseases such as malaria will need greater public investment in the order of $\$ 250$ million over the next decade, "and these vaccines will not reach their final development stage without the active support of WHO in coordinating clinical trials in last few decades to broaden access to vaccines, Bellamy stressed that half of the children in sub-Saharan Africa have never been immunized and around 12 million children still die every year from preventable diseases such as measles, pneumonia, diarrhea and malaria.

Despite this censure, Bellamy said that UNICEF and the World Health Organization (WHO) were "excited" by the breakthroughs in science and biotechnology that are making new vaccines possible: "today, there are predictions that as many as 20-30 additional vaccines may come on line over the next two decades."

She singled out two vaccines that have recently received marketing approvalagainst rotavirus and pneuomococcus- as having the potential to prevent around 2

\section{affected countries," she warned.}

Bellamy also made an appeal for the children of the 47 poorest countries (Band A-see Batson, page 487) to receive vaccines free of charge. Although nearly 80 percent of the 130 million children born worldwide each year now receive vaccinations against diphtheria, tetanus, whooping cough, polio, measles and tuberculosis-thanks largely to the Expanded Program on Immunization (EPI) campaign launched by WHO in 1974-the cost of coverage against these diseases as well as hepatitis B and yellow fever for children in Band A is $\$ 70$ million. Adding Haemophilus influenzae type b (Hib)and rotavirus vaccine coverage raises the cost to $\$ 225$ million and pneu- mococcal vaccination further increases the price tag to $\$ 381$ million.

UNICEF is committed to raising funds for Band A immunization and

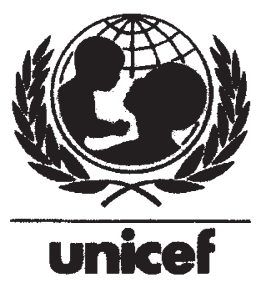
Bellamy asked that the private sector keeps prices at affordable levels. She commended the tiered pricing system, which enables the poorest countries to receive vaccines at prices they can afford, as being the cornerstone of private-public partnership in vaccines.

Bellamy listed 90 percent worldwide coverage with four EPI vaccines (diphtheria, polio, measles and tuberculosis) as one of four UNICEF targets for 2000, in addition to eliminating neonatal tetanus, eradicating poliomyelitis and achieving a 95 percent reduction in measles mortality. Goals for 2010 include reducing deaths due to Hib pneumonia and meningitis by 80 percent and introducing vaccines against malaria and, hopefully, HIV.

Bellamy concluded her speech by calling on the scientific community and the private sector to join UNICEF and WHO in ensuring that "all children enjoy the practical health benefits made possible by existing vaccines, vaccines under development and vaccines of the future."

KAREN BirminghaM, NEW YORK

\section{Panel recommends White House coordinates AIDS vaccine development}

Twelve months ago, President Clinton declared the US government's commitment to producing an AIDS vaccine within ten years. His statement was based, in large part, on the recommendations of the Presidential Advisory Council on HIV/AIDS (PACHA) - a 33 member panel made up of government, academic and advocacy representatives-charged with advising the President on the direction of AIDS research. But after one year with what some regard to be little progressfew vaccine candidates in the pipeline, no Phase III clinical trials, no director of the new NIH Vaccine Research Laboratory and no one to replace William Paul as NIH AIDS coordinator-some PACHA members have become restless and doubt that the goal will be met.
Consequently, the council has passed a new resolution calling for tighter control of the AIDS vaccine development process through the White House's Office of National AIDS Policy (ONAP) led by Sandra Thurman and for ONAP to implement "a comprehensive federal plan to achieve the goal of an effective AIDS vaccine."

Moreover, PACHA has repeated its belief that if the President's goal is to be met, other agencies in addition to the NIH must be involved.

The council states that the Centers for Disease Control and Prevention, Department of Defense and the United States Agency for International Development have "extensive experience and expertise in the area of vaccine devel- opment, field epidemiology, surveillance and the conduct of vaccine efficacy trials," and should be more involved in the AIDS IMAGE vaccine program. UNAVAILABL Despite interagency cooperation also E FOR COPYRIGHT the 1996 Levine REASONS Report, so far only informal meetings between these groups have taken place. There is

still no proper process of communication involving senior leadership from the agencies, says PACHA.

These proposals mark a return to draft recommendations made by PACHA prior to the President's May 1997 speech, and are certain to protract the discord between those that favor an empirical route to an 